\title{
The stable tungsten isotope composition of seawater and Mn-rich sediments from the Baltic Sea
}

\author{
F. KURZWEIL ${ }^{1 *}$, C. ARCHER ${ }^{2}$, M. WILLE ${ }^{3}$, R.

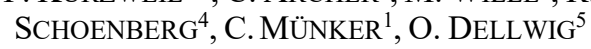 \\ ${ }^{1}$ Institut für Geologie und Mineralogie, Universität zu Köln, \\ Germany (*correspondence: fkurzwei@uni-koeln.de) \\ ${ }^{2}$ ETH Zürich, Switzerland \\ ${ }^{3}$ University of Bern, Switzerland \\ ${ }^{4}$ Eberhard Karls Universität Tübingen, Germany \\ ${ }^{5}$ Leibnitz-Institute for Baltic Sea Research, Germany
}

Manganese oxides are a major sink for dissolved marine $\mathrm{WO}_{4}{ }^{2-}$ and $\mathrm{MoO}_{4}{ }^{2-}$. During adsorption of $\mathrm{WO}_{4}{ }^{2-}$ and $\mathrm{MoO}_{4}{ }^{2-}$ onto $\mathrm{Mn}$ oxides the coordination of $\mathrm{W}$ and Mo changes from tetrahedral to octahedral [1]. Light isotopes are preferentially adsorbed due to the weaker bonding structure in octahedral coordination. Sulfidic settings are another major sink for Mo, but not for $\mathrm{W}$ [2]. In contrast to Mo, the $\delta^{186 / 184} \mathrm{~W}$ of seawater and authigenic sediments is therefore expected to be independent of the global extension of (weakly) sulfidic conditions but more intimately linked to the extension of oxic marine conditions.

We present the first stable $\mathrm{W}$ isotope data of a sedimentary sequence from the Landsort Deep, Baltic Sea, covering the last $\sim 1,700$ yrs. Within this funnelshaped basin distinct vertical stratification causing bottom water euxinia alternated with fully oxic/hypoxic conditions. During oxic periods, e.g. little Ice Age, detrital $\mathrm{W}$ and $\mathrm{Mn}$ components dominate and $\delta^{186 / 184} \mathrm{~W}$ are close to the upper mantle value of $+0.085 \pm 0.019 \%$ o [3]. Sediments deposited during periods of hypoxia are authigenically enriched in $\mathrm{W}$ and $\mathrm{Mn}$ and show higher $\delta^{186 / 184} \mathrm{~W}$ up to $+0.226 \%$, although Mn-oxides preferentially adsorb light $\mathrm{W}$. These heavy signals might result from even heavier seawater $\delta^{186 / 184} \mathrm{~W}$, as also indicated by our first analyses for South Atlantic seawater $(+0.545 \pm 0.051 \%)$. Our results contribute to the understanding of stable $\mathrm{W}$ isotope systematics in modern marine sedimentary settings, which is required to establish stable $\mathrm{W}$ isotopes as a potential tracer for Early Earth environmental reconstructions.

[1] Kashiwabara et al. (2017) GCA 106, 364-378. [2] Mohajerin et al. (2016) GCA 177, 105-119. [3] Kurzweil et al. (2019) GCA 251, 176-191. 